\title{
XIAP: a potential determinant of ovarian follicular fate
}

\author{
Hollian R Phillipps ${ }^{1,2}$ and Peter R Hurst ${ }^{1,2}$ \\ ${ }^{1}$ Department of Anatomy, School of Medical Sciences, University of Otago, Dunedin 9016, New Zealand and \\ ${ }^{2}$ Centre for Reproduction and Genomics, Invermay Agricultural Centre, Mosgiel, Dunedin 9053, New Zealand
}

Correspondence should be addressed to H R Phillipps at Department of Anatomy, University of Otago, PO Box 913, Dunedin 9054, New Zealand; Email: hollian.phillipps@anatomy.otago.ac.nz

\begin{abstract}
X-linked inhibitor of apoptosis protein (XIAP), a member of the inhibitor of apoptosis protein family, is involved in regulating a number of functions including receptor-mediated intracellular signalling and early development. Its role as an endogenous caspase inhibitor, however, is the most highly characterised. Consequently, this protein has been implicated as an anti-apoptotic factor in the ovary. In vitro and in vivo studies have begun dissecting the stimuli and signalling networks that lead to XIAP upregulation in granulosa cells. The objective of this review is to briefly summarise the current knowledge concerning XIAP and its interactions with different caspases. Furthermore, XIAP's emerging role in the mammalian ovary will be explored and comparison is made with its functions in the mammary gland. Finally, the idea that XIAP may act as a molecular signalling switch in granulosa cells following detachment from underlying layers to promote follicular atresia will be introduced.

Reproduction (2012) 144 165-176
\end{abstract}

\section{Introduction}

The inhibitor of apoptosis (IAP) gene was first discovered almost 20 years ago in an assay investigating functional p35 homologues in baculoviruses (Crook et al. 1993). Subsequently, a number of orthologues have been identified in different species, ranging from yeast to mammals (Uren et al. 1998). At present, there are eight members of the mammalian IAP protein family of which X-linked inhibitor of apoptosis protein (XIAP) (also referred to as baculoviral IAP repeat (BIR) containing protein 4 (BIRC4)) is the most highly documented. This review focuses on XIAP's role and regulation in ovarian tissue and provides a comparison with its function in the mammary gland. Moreover, a hypothetical model that XIAP acts as a critical signalling switch in granulosa cells to induce follicular atresia is proposed.

\section{Inhibitor of apoptosis proteins}

IAPs are involved in a number of roles within cells, including cell cycle control and copper homeostasis (Galvan et al. 2004, Mufti et al. 2006). Their ability to act as anti-apoptotic factors, however, has received considerable attention, particularly in the field of cancer biology as breakdown in the regulation of cell death signalling can have substantial consequences, such as malignant cell growth. Despite this, our knowledge regarding the mechanism/s underlying IAP function, particularly in normal physiology, is limited.
In particular, XIAP has been identified in a number of cell types in the healthy ovary, including stromal tissue, ovarian surface epithelium (OSE), granulosa cells (Fig. 1), thecal cells (Fig. 1), oocytes and luteal cells (Li et al. 1998, Lareu et al. 2003, Vischioni et al. 2006, Cheng et al. 2008, Phillipps et al. 2011). Several studies have localised XIAP expression at different stages during folliculogenesis. In rats, XIAP is present in granulosa cells, thecal tissue and oocytes within follicles from the preantral stage onwards (Li et al. 1998). Moreover, subsequent studies in pigs and sheep have confirmed granulosa and thecal cell expression in antral follicles (Cheng et al. 2008, Phillipps et al. 2011). In sheep, XIAP has been detected at the protein level early in development in primary staged follicles up to large antral follicles (Phillipps et al. 2011). This widespread expression across cell types and follicle stages suggests that XIAP and potentially IAPs in general are pivotal factors involved in regulating the dynamic environment within the ovary.

\section{IAP key structural components}

IAPs are classed in accordance with the existence of one to three BIR domains within their structure (Hinds et al. 1999). The BIR domains are around $70-80$ amino acids in length, the first of which is located near the protein's amino terminal (N-terminal), and coordinate a zinc ion within their core via several cysteine residues and a single histidine residue (Hinds et al. 1999, 
A

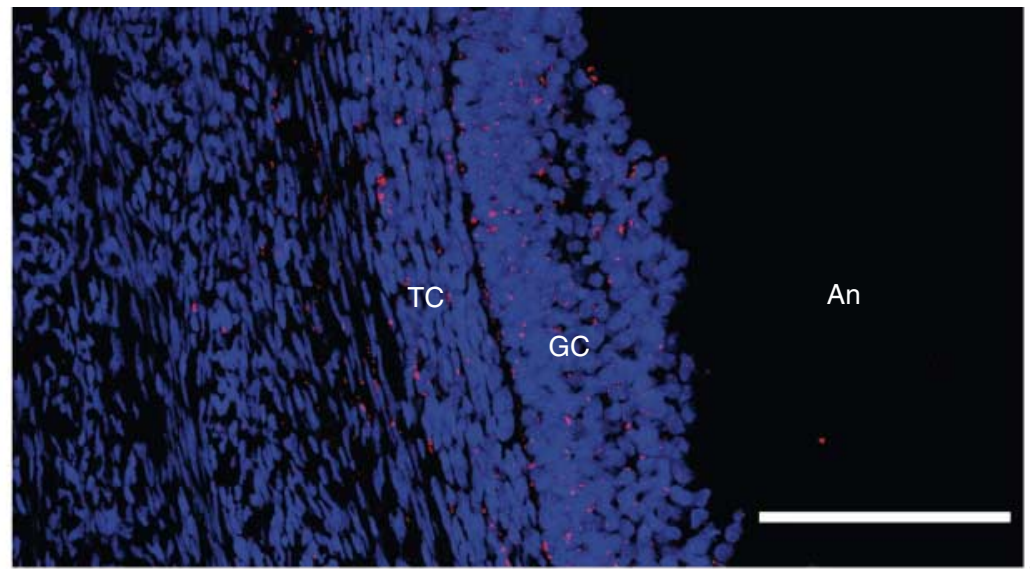

B
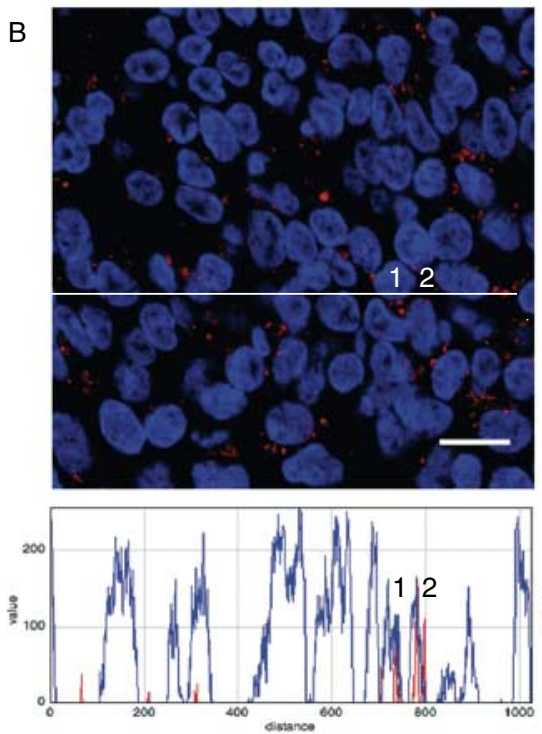
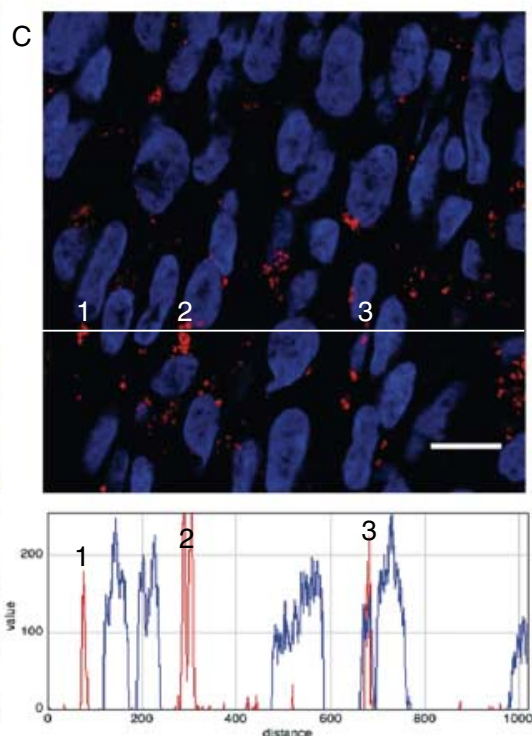

Figure 1 Localisation pattern of XIAP in sheep antral follicle granulosa and thecal cells using confocal microscopy. Immunofluorescent signals for XIAP (red, Alexa Fluor 555, Molecular Probes, Inc., Eugene, OR, USA) and nuclei marker (blue TO-PRO-3, Molecular Probes, Inc.). Fluorescent signals in (B) and (C) bisected by white lines are shown in the RGB graphical output below each image. (A) Antral follicle showing XIAP expression present in both granulosa (GC) and thecal (TC) cell layers. (An), antral space. (B and C) Adjacent optical slices ( $1.5 \mu \mathrm{m}$ thickness) taken from a Z stack showing a $425 \mu \mathrm{m}^{2}$ area of granulosa or thecal tissue. XIAP expression in both cell types is predominately located in the cytoplasm (red) and occasional nuclear expression (pink) is evident. In (B), the corresponding graph shows perinuclear XIAP expression (1) and regions of red and blue fluorescent signals overlapping to give a pink signal indicative of XIAP nuclear expression in one or two cells (2). In (C), the corresponding graph shows two areas of XIAP cytoplasmic expression (single red peaks 1 and 2) and an area of nuclear expression indicated by the red and blue overlapping peaks (3). Scale bars (A) $100 \mu \mathrm{m}$, (B and C) $10 \mu \mathrm{m}$.
Sun et al. 1999, 2000, Liu et al. 2000, Lin et al. 2007). The presence of multiple BIR domains enables IAPs, such as cellular IAP (CIAP) 1, cIAP2 and XIAP, to interact with a number of different proteins. Distinct functions for each BIR domain have been identified, for example domains BIR2 and BIR3 of XIAP interact with caspases-3/7 and caspase-9 respectively (Fig. 2; Takahashi et al. 1998). The XIAP antagonist second mitochondrial activator of caspases/direct IAP binding protein with low pl (Smac/DIABLO) binds sequentially to the BIR3 and then BIR2 domains (Gao et al. 2007). Smac/DIABLO uses steric hindrance and mutual exclusion to prevent caspases-3/7 and caspase- 9 respectively, from binding to XIAP, thereby allowing activation of apoptotic signalling (Fig. 2; Wu et al. 2000). XIAP's BIR1 domain, however, does not target caspases but has been shown to play a role in signalling by adopting a homodimer formation when interacting with transforming growth factor $\beta$ (TGF $\beta$ )-activated kinase binding protein (TAB1) enabling activation of TGF $\beta$-activated kinase 1 (TAK1) and subsequent downstream nuclear factor $\kappa B(N F-\kappa B)$ signalling (Fig. 2; Lin et al. 2007,
Lu et al. 2007). Moreover, BIR domains, despite being highly conserved, also show functional diversity between different IAP proteins due to changes in pivotal surface residues. A single BIR1 domain in CIAP1 and CIAP2, but not XIAP, can bind to tumour necrosis factor (TNF) receptor-associated factor (TRAF) 2, an adaptor molecule involved in TNF signalling, thereby preventing apoptosis (Samuel et al. 2006, Mace et al. 2010). A ubiquitin-associated (UBA) domain located in the linker region following the BIR3 domain and a carboxyl terminal really interesting new gene 1 (RING) zinc finger (RZF) domain are also present within IAPs that contain three BIR domains, including CIAP1, CIAP2 and XIAP (Fig. 2). The UBA domain enables IAPs to bind ubiquitin via a conserved hydrophobic residue sequence (Blankenship et al. 2009). An in vitro study has shown that E3 ubiquitin ligase activity and capability of binding ubiquitin are necessary for XIAP-induced activation of

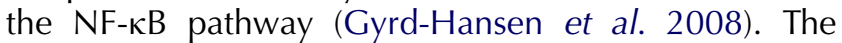
RZF domain contributes to protein ubiquitination by conferring E3 ubiquitin ligase activity enabling selfregulation of IAP expression levels, alteration of IAP 


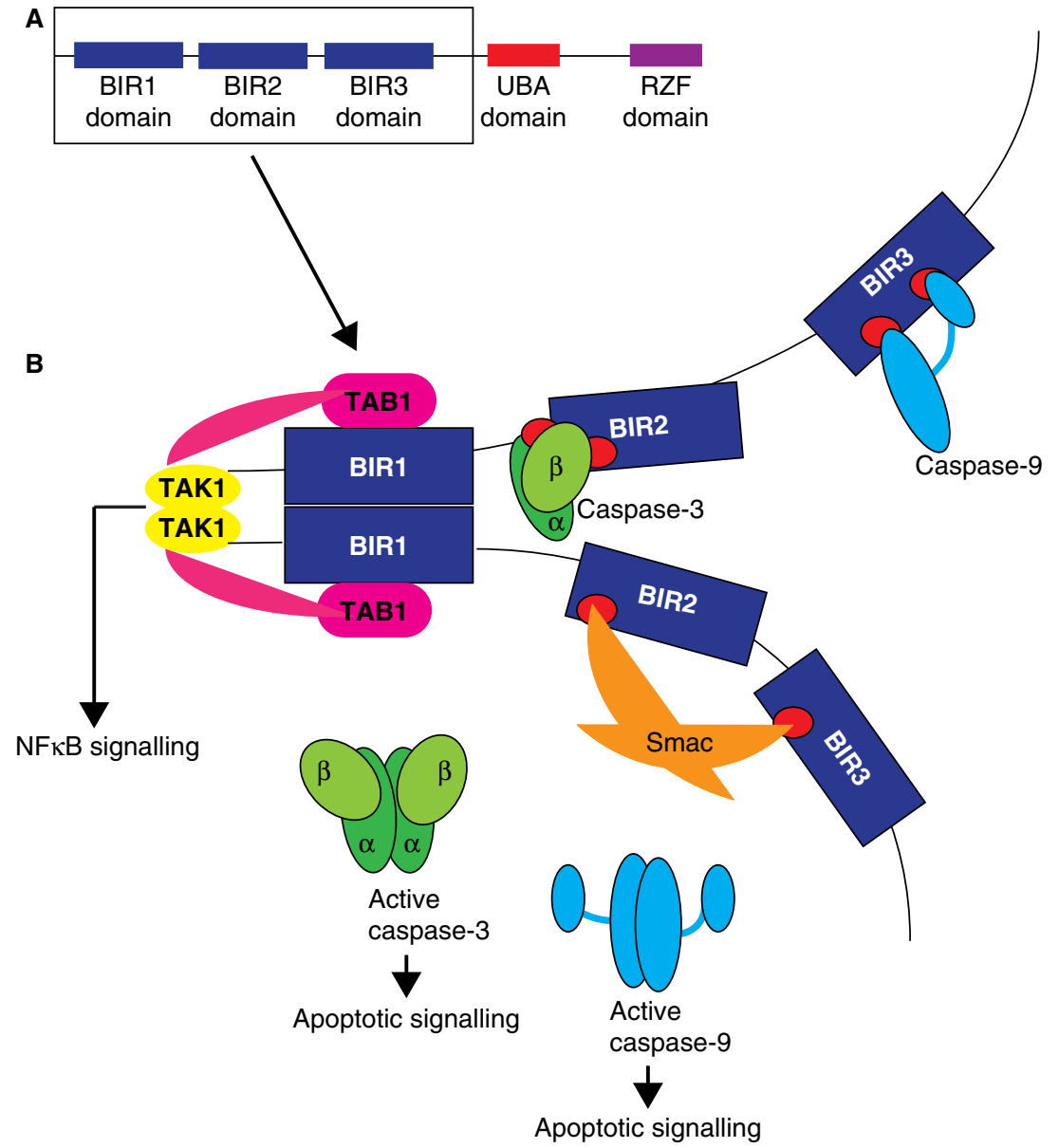

Figure 2 Interactions of XIAP's BIR domains (A) The organisation of different domains within XIAP's sequence. The baculoviral IAP repeat (BIR) domains are shown in blue, a ubiquitinassociated (UBA) domain is in red and the C-terminal RING zinc finger (RZF) domain is in purple. (B) This shows a larger image of the three BIR domains (boxed area in A) from two XIAP sequences. The BIR1 domain is shown forming a homodimer when interacting with TAB1 promoting activation of TAK1 and subsequent downstream signalling. In the top XIAP sequence, caspase- 3 is bound at two binding sites (red), one within the linker sequence before the BIR2 domain and the second the IBM interacting groove within the BIR2 domain. Alternatively, the BIR3 domain binds at two sites (red) to caspase-9 forming a heterodimer. These two interactions prevent caspase activation. In the other XIAP sequence, the binding sites (red) within BIR domains 2 and 3 are bound to Smac, which prevents XIAP-induced caspase inhibition. levels by other IAP family members and targeting bound proteins for degradation by the proteasome (Yang et al. 2000, Silke et al. 2005, Schile et al. 2008).

\section{Mechanisms regulating XIAP synthesis and degradation}

XIAP synthesis is controlled at both the levels of transcription and translation. Gene expression of IAPs, including XIAP, CIAP1 (BIRC2) and CIAP2 (BIRC3) is regulated by stress-inducible transcription factors such as NF- $\mathrm{KB}$, as has been demonstrated in cultured endothelial cells treated with inflammatory cytokines (Stehlik et al. 1998). However, XIAP, unlike other IAPs, is predominantly regulated at the level of translation. A study screening mutant human XIAP 5'-UTR mRNA constructs has identified an internal ribosome entry site present -162 to -1 upstream of the start codon (Holcik et al. 1999). This motif enables recruitment of the small (40S) ribosomal/Met-tRNAi complex to the start codon eliminating ribosome scanning of the $5^{\prime}$-UTR for appropriate start codons and cap-binding steps (Sonenberg \& Hinnebusch 2009). Consequently, continued translation of XIAP occurs within a cell in the presence of apoptotic and/or stress stimuli, despite a decrease in cap-dependent translation. Furthermore, two XIAP mRNA transcripts with variable $5^{\prime}$-UTR lengths have been identified. These isoforms are subject to either cap-dependent or -independent translational control under different cellular conditions (Riley et al. 2010). This suggests that XIAP levels are regulated by interplay between different mRNA isoforms and translation initiation mechanisms effectively maintaining appropriate levels across different cell states.

Degradation of XIAP as mentioned previously can be self-regulated by its E3 ubiquitin ligase activity or by other IAP family members; however, a number of proteins including XIAP-associated factor 1 (XAF1), $\mathrm{Omi} / \mathrm{HtrA} 2$ and apoptosis-related protein in the TGF $\beta$ signalling pathway (ARTS) also act to reduce XIAP levels using a number of mechanisms. XAF1 acts to neutralise endogenous or overexpressed XIAP by relocating and sequestering it from the cytoplasm to the nucleus (Liston et al. 2001). This action, however, does not promote degradation of XIAP. XAF1 can form a complex with XIAP and induce reactivation of XIAP's E3 ligase activity following inhibition imposed by survivin bound to XIAP (Arora et al. 2007). This leads to degradation of survivin and presumably self-degradation of XIAP levels (Arora et al. 2007). Omi/HtrA2, a serine protease released from 
the mitochondria during apoptosis, interacts with IAPs, including XIAP via their IAP binding motif (IBM) using a similar mechanism to Smac/DIABLO to alleviate caspase inhibition (Hegde et al. 2002). Interaction of Omi/HtrA2 with XIAP increases its proteolytic activity, and subsequent proteolytic cleavage of XIAP leads to irreversible degradation (Martins et al. 2003). Finally, ARTS, another mitochondrial protein released into the cytosol during apoptosis, uses an alternate mechanism to those described earlier to promote XIAP degradation. This protein connects the E3 ligase seven in absentia homolog 1 (Siah-1) to XIAP by interacting with XIAP's BIR1 and -3 domains (Garrison et al. 2011). This linkage targets XIAP for ubiquitination and degradation (Garrison et al. 2011).

\section{XIAP and caspases}

The adult mammalian ovary is an ideal model to study apoptosis, as ovarian follicles continuously grow, develop and undergo selection leading to induction of follicular atresia in a vast proportion. XIAP has been shown to be the only IAP capable of strong direct caspase inhibition leading to termination of apoptotic signalling (Eckelman \& Salvesen 2006). Despite this, it has received limited attention in the field of reproductive biology. This may be due to Xiap-deficient mice initially thought to have no obvious defects in apoptotic signalling and normal fertility, suggesting the possibility of other IAP family members, such as clAP1/2, compensating for XIAP loss (Harlin et al. 2001). More recent research, however, has shown elevated caspase-3 activity in response to TNF $\alpha / \mathrm{CHX}$-induced apoptosis occurring in mouse embryonic fibroblasts derived from Xiap-deficient mice. Therefore, further studies focusing on specific cell types derived from this mouse model are required to gain a more comprehensive understanding of XIAP function (Schile et al. 2008).

XIAP regulates apoptotic signalling by a direct interaction with caspase targets, including caspases-3, -7 and -9 (Eckelman \& Salvesen 2006). Caspases are a family of cysteine proteases produced in cells in an inactive state (procaspases) (Alnemri et al. 1996). They can be grouped based on the number of residues in their prodomain and entry position in the apoptotic pathway as either initiators (or apical) or effectors (executioners) (Fuentes-Prior \& Salvesen 2004, Kumar 2007). Initiator caspases, for example caspase-9, contain long prodomains (>90 amino acids in length) with homotypic interaction motifs such as caspase recruitment domains (Bao \& Shi 2007). These motifs mediate recruitment to adaptor protein complexes, for example the apoptosome that includes caspase-9 and allow subsequent activation via induced proximity dimerisation and multiple aspartic acid residue autocleavage events (Pop et al. 2006, Oberst et al. 2010). Initiator caspases, unlike effector caspases including caspases-3 and -7, are stored in cells as inactive dimers and subsequently cleaved at specific aspartate residues within their intersubunit linker sequence by active initiator caspases to release their small $\beta$ and large $\alpha$ subunits (Fuentes-Prior \& Salvesen 2004). These separated subunits subsequently form heterodimers $(\alpha / \beta)$ and two heterodimers associate together to form an enzymatically active mature tetramer $(\alpha \beta)_{2}$ formation, which can undertake controlled dismantling of cellular components (Rotonda et al. 1996, Pop et al. 2001).

In mammals, caspases act in two differentially stimulated apoptotic signalling cascades, the intrinsic and extrinsic pathways, to execute cell death. The intrinsic pathway is activated by release of cytochrome $c$ from the mitochondria in response to an apoptotic stimulus. Cytochrome $c$ interacts with its cellular receptor Apaf-1 and in the presence of dATP or ATP the apoptosome is formed (Zou et al. 1997, 1999). In contrast, the extrinsic pathway relies on ligand binding to TNF family transmembrane death receptors, for example Fas receptor (Bao \& Shi 2007). Fas ligand binding to Fas receptors induces recruitment of Fas-associated protein with death domain (FADD; Bao \& Shi 2007, Scott et al. 2008). Homotypic interaction between death effector domains (DEDs) within FADD and procaspase-8 leads to recruitment of this caspase to form a deathinducing signalling complex and subsequent caspase-8 activation (Muzio et al. 1996, Bao \& Shi 2007, Scott et al. 2008).

XIAP uses a two-site binding mechanism to inhibit active caspases- 3 and -7 . First, the $\mathrm{N}$-terminal linker sequence preceding the BIR2 domain interacts in a reverse orientation with caspases-3/7 substrate binding cleft (active site) preventing access to additional substrates (Sun et al. 1999, Chai et al. 2001, Huang et al. 2001, Riedl et al. 2001, Scott et al. 2005). The caspase-7/XIAP interaction differs slightly from caspase3 as a portion of the $\mathrm{N}$-terminal in addition to the active site is involved. This suggests that inhibition of caspase-7 via a non-competitive means is also occurring (Suzuki et al. 2001). Stabilisation of the XIAP linker/caspase active site interaction has been suggested to occur by the second binding site, the IBM interacting groove in the BIR2 domain associating with the IBM in the $\mathrm{N}$-terminal of caspases-3 and -7's small $\beta$ subunit (Sun et al. 1999, Scott et al. 2005). The relative importance of this second interaction site to overall caspase inhibition, however, has been argued in a study involving permanent denaturation of XIAP's BIR2 domain, which suggested that BIR2 binding was insignificant and conformational access to the linker sequence was pivotal for adequate inhibition (Abhari \& Davoodi 2010). Despite this disagreement, crucial residues, such as aspartic acid 148, within the linker sequence necessary for adequate caspase inhibition have been identified through mutagenesis analysis (Sun et al. 1999, Scott et al. 2005). Caspase- 9 in its monomeric form is inhibited by XIAP by formation of a heterodimer through the same dimeric 
interface as homodimer activation occurs (Shiozaki et al. 2003). This maintains both procaspase- 9 and its processed form in an inactive conformation, consequently, preventing activation of effector caspases (Shiozaki et al. 2003). Inhibition is achieved through interaction of two sites within its BIR3 domain. The surface BIR3 domain IBM binding groove binds to the IBM on caspase-9's small subunit and stabilises another interaction between the caspase's dimeric interface and XIAP's BIR3 domain (Shiozaki et al. 2003).

\section{XIAP roles in the ovary}

XIAP's ability to inhibit caspases and its expression pattern in the ovary suggests a potential role as a critical regulator of follicular atresia. In rats, a reduction in XIAP levels in increasingly atretic mid-to-late stage antral follicles has been shown and subsequent biochemical analysis confirmed an inverse relationship ( $\mathrm{Li}$ et al. 1998). Furthermore, a transition from predominant nuclear to cytoplasmic expression in rat granulosa cells coinciding with the onset of atresia has been observed (Li et al. 1998). This localisation change, however, did not occur in sheep, highlighting potential variation in XIAP expression patterning in relation to atresia in ruminants and rodents (Phillipps et al. 2011). A decrease in XIAP mRNA and protein expression levels has been observed with increasing atresia as determined by in situ TUNEL and changes to antral follicular fluid ratios of $17 \beta$-oestradiol $\left(\mathrm{E}_{2}\right) /$ progesterone in porcine ovarian follicles (Cheng et al. 2008). Furthermore, a proportion of sheep antral follicles present during the follicular phase show decreasing XIAP expression levels with increasing active caspase- 3 immunoreactivity (Phillipps et al. 2011). In our laboratory, confocal imaging has also demonstrated protein colocalisation of active caspase- 3 and XIAP in the cytoplasm of antral follicle granulosa cells, suggesting that direct caspase inhibition is a likely mechanism (Fig. 3). Interestingly, sites of colocalisation were found alongside expression of XIAP and active caspase- 3 protein alone and no colocalisation was detected in antral follicles during the luteal phase.

Investigation of XIAP's role in luteal cells has shown a reduction in XIAP expression, similar to that seen during follicular atresia, coinciding with regression of this structure at the post partum stage in rats (Lareu et al. 2003). Consequently, it has been suggested that XIAP promotes survival, and a measured reduction of XIAP levels in luteal cells over subsequent oestrous cycles provides a mechanism for its gradual demise (Lareu et al. 2003). There is also evidence that XIAP is involved in regulation of cell turnover in other ovarian cell types. For example, overexpression of XIAP in cultured human OSE cells containing a mutation in the BRCA1 gene leads to restoration of active caspase- 3 ubiquitination and a subsequent reduction in caspase-3 levels Johnson et al. 2004).
Widespread XIAP expression in the ovary, particularly in cell types such as thecal cells (Fig. 1), which appear to have an increased resistance to apoptosis, has led to the suggestion of XIAP involvement in other functions, independent of cell survival (Li et al. 1998, Lai et al. 2003, Phillipps et al. 2011). In rats, the intensity of XIAP expression in thecal cells from growing follicles is higher than that in granulosa cells in the same follicles ( $\mathrm{Li}$ et al. 1998, Lai et al. 2003). Consequently, XIAP involvement in thecal cell differentiation has been proposed, although supporting evidence for this is limited (Lai et al. 2003). In sheep, positive XIAP expression has been observed in stromal cells surrounding some primary follicles further implicating a possible role in thecal cell recruitment and differentiation (Phillipps et al. 2011).

\section{Regulation of XIAP in the ovary}

An extensive signalling network involving XIAP in ovarian follicles is beginning to be characterised through the use of a number of in vivo and in vitro approaches (Figs 4 and 5). Not surprisingly, FSH induces upregulation of XIAP levels in both cultured rat granulosa cells and preantral to antral stage follicles (Asselin et al. 2001, Wang et al. 2002a, 2003). This has been shown to coincide with a reduction in DNA fragmentation associated with apoptosis and increased phosphorylated-Akt (P-Akt) levels implicating the phosphatidylinositol 3-kinase/Akt (PI3K/Akt) survival pathway in XIAP signalling (Asselin et al. 2001, Wang et al. 2003). In fact, infection of adenoviral XIAP anti-sense or sense cDNA into granulosa cells has demonstrated XIAP regulation of phospho-Akt content (Asselin et al. 2001). Moreover, XIAP has been shown to be a substrate phosphorylated by Akt in a study using cell lines including ovarian cancer epithelial cells (Dan et al. 2004). Phosphorylation of XIAP at serine-87 (S87) leads to increased stability and confers protection from auto- and targeted ubiquitination and degradation while still retaining the ability to inhibit caspases in cells treated with cisplatin (Dan et al. 2004).

Investigation into the underlying mechanism of gonadotrophin-induced XIAP expression has demonstrated an oestrogen-dependent increase in XIAP levels in rat-cultured follicles and isolated granulosa cells in response to TGF $\alpha$ (Wang et al. 2002a). This effect has been proposed to occur by $E_{2}$ produced in granulosa cells in response to $\mathrm{FSH}$, acting on thecal cells to promote secretion of TGF $\alpha$, which then binds to its receptor on granulosa cells and induces upregulation of XIAP levels (Wang et al. 2002a). Involvement of NF-KB signalling has also been implicated in $\mathrm{FSH}$-induced XIAP expression in granulosa cells. This stems from an in vitro study, which demonstrated FSH-stimulated activation of NF- $\kappa B$ occurring through the PI3K/Akt signalling pathway (Wang et al. 2002b). TNF $\alpha$ also uses a NF-KB regulatory mechanism to increase XIAP content in 
A
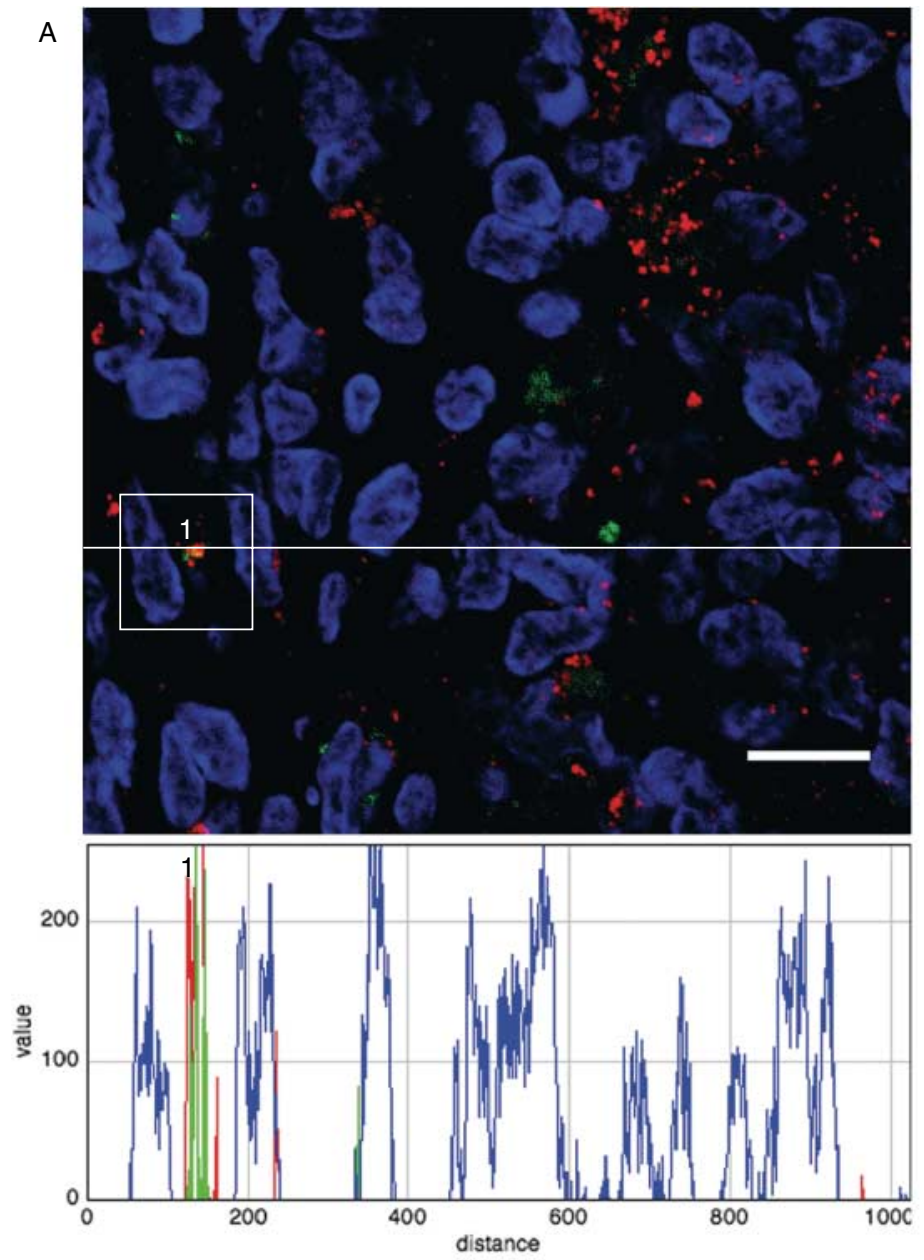

B
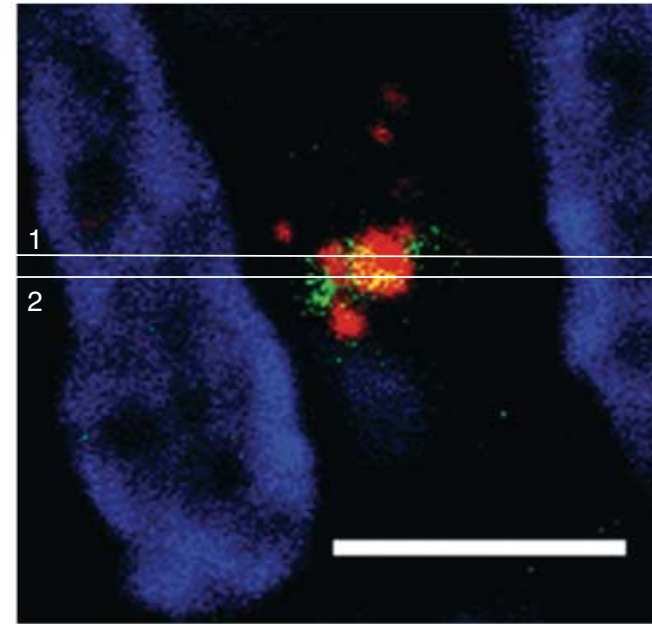

1

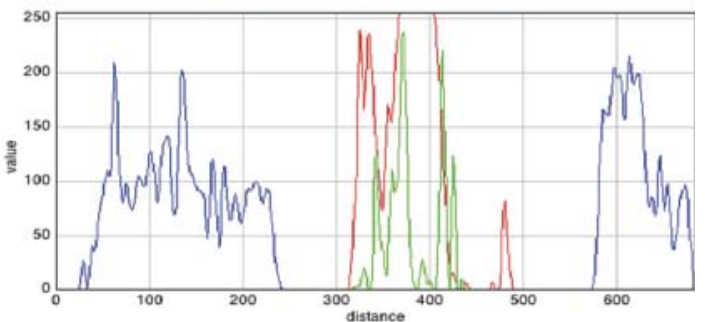

2

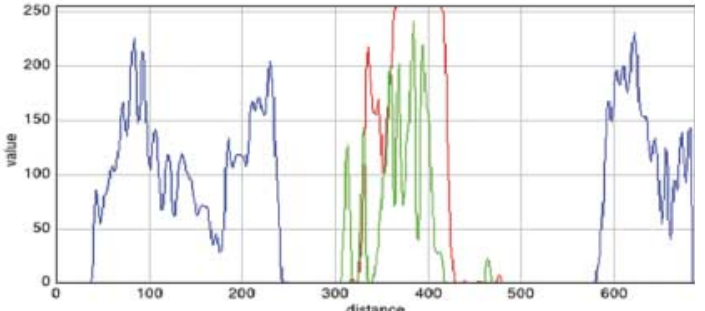

Figure 3 High-resolution confocal imaging of XIAP and active caspase-3 protein colocalisation in granulosa tissue. (A) An area of granulosa cell wall $\left(425 \mathrm{\mu m}^{2}\right.$ ) showing XIAP (red, Alexa Fluor 555; Molecular Probes, Inc., Eugene, OR, USA) and active caspase-3 (green, Alexa Fluor 488, Molecular Probes, Inc.) cytoplasmic expression and nuclear localisation of XIAP (pink). Individual nuclei are in blue (TO-PRO-3; Molecular Probes, Inc.). Cytoplasmic colocalisation of XIAP and active caspase-3 protein (yellow) is shown bisected by the white line (1). This localisation pattern is depicted in the red, green, blue (RGB) graphical output below as red and green overlapping peaks (1). (B) Larger image of the boxed area in A. Sites of active caspase-3 protein and XIAP colocalisation are apparent (yellow), alongside expression of these two proteins alone (red (XIAP) and green (active caspase-3)) within the cytoplasm of a single cell. Part of two different nuclei are evident either side of the cytoplasmic colocalisation. The two graphs below this image depict two different levels where the white line has bisected through the colocalised fluorescent signals (1 and 2). Scale bars (A) $10 \mu \mathrm{m}$ and (B) $5 \mu \mathrm{m}$.

granulosa cells. This, however, is thought to involve I BB-NF- $\kappa B$ signalling as treatment of granulosa cells with $\mathrm{TNF} \alpha$ resulted in a rapid elevation in phosphorylated

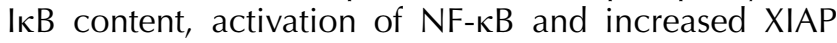
levels (Xiao et al. 2001). A gonadotrophic regulatory mechanism between the PI3K/Akt pathway and the TGF $\beta$ family member nodal's receptor, activin receptor like kinase 7 (ALK7), has also been proposed. Nodal has been detected primarily in thecal tissue in antral follicles during folliculogenesis and shown to colocalise with its receptor in granulosa cells within atretic follicles following gonadotrophic withdrawal (Wang et al. 2006). Furthermore, nodal induces granulosa cell apoptosis by activation of Smad2 signalling (Wang et al. 2006). This leads to downregulation of XIAP levels at both the protein and mRNA level (Wang et al. 2006). Moreover, activation of Akt reduces granulosa cell ALK7 levels, and overexpression of nodal in culture leads to significantly lower P-Akt content (Wang et al. 2006). This regulation is likely to have opposing effects on XIAP content in granulosa cells.

Thecal cell BMP7 has also been shown to promote an elevation in XIAP levels in bovine granulosa cells. In contrast, BMP4 may act as a potent XIAP inhibitor as treatment of bovine granulosa cells with BMP4 or BMP4 and BMP7 together did not affect XIAP levels 


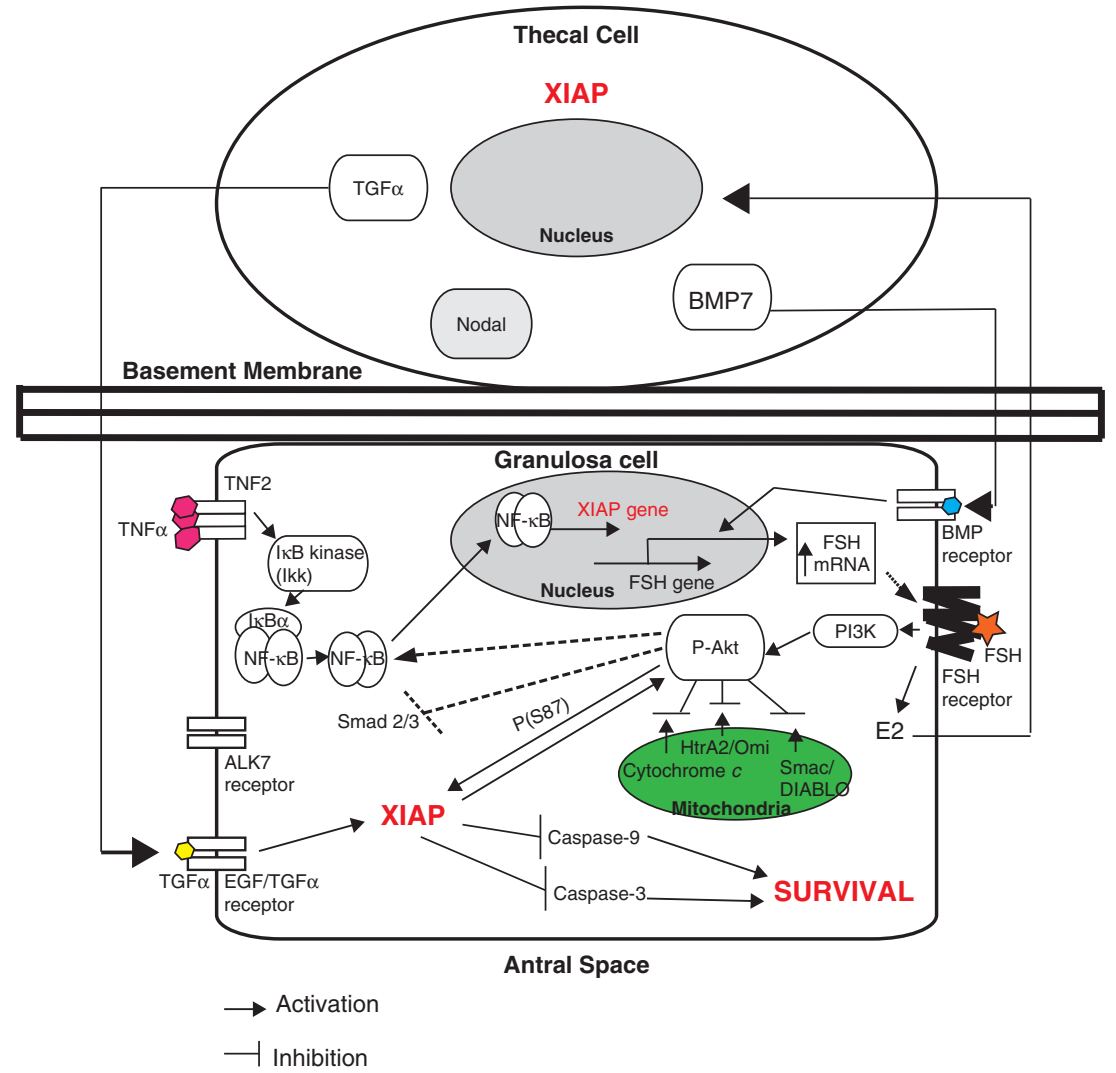

Figure 4 Proposed model of XIAP regulation in granulosa and thecal tissues from a healthy antral follicle. Dashed lines and arrows represent proposed signalling links; however, further studies are required to validate these interactions. Refer to text under 'Regulation of XIAP in the ovary' for further details and references.
(Kayamori et al. 2009). In addition, both BMPs stimulated expression of survivin, another IAP family member. A recent study using cultured luteinised human granulosa cells has shown that BMP7 can induce increased expression of FSH receptor mRNA (Shi et al. 2010). This may provide a mechanism for BMP7 regulation of XIAP; however, additional studies are required to confirm this. Furthermore, both BMP4 and BMP7 can promote granulosa cell survival, suggesting that these proteins may act through XIAP-dependent and -independent mechanisms (Kayamori et al. 2009).

\section{Other IAPs in the ovary}

XIAP is not the only IAP family member acting in ovarian tissue. Neuronal apoptosis inhibitory protein (NAIP) and survivin have been detected in granulosa cells from primary follicles up to the preovulatory stage. Moreover, like XIAP, expression of these IAPs is stimulated by gonadotrophins (Matsumoto et al. 1999, Kumazawa et al. 2004). A relationship between low Naip1 (Naip) mRNA expression levels in granulosa cells and reduced ovulated oocyte quality has been observed, indicating that NAIP may act indirectly to promote oocyte viability in the mouse ovary (Matsumoto et al. 1999). Furthermore, immunoreactivity for survivin in oocytes has been observed at all follicle stages, and this IAP has been shown to play a direct role in meiotic maturation. Studies investigating the intracellular localisation of survivin have shown localisation and expression intensity changes during oocyte meiotic stage progression (Sun et al. 2009, Wang et al. 2011). Initially, survivin is highly expressed in the germinal vesicle. As the oocyte transitions from prometaphase I to metaphase I, redistribution to the kinetochores/centromeres occurs and low expression on the chromosome arms is evident. By anaphase and telophase, survivin localises to the spindle midzone and midbody respectively. Moreover, a similar expression pattern is evident at metaphase II similar to that seen in metaphase I (Sun et al. 2009, Wang et al. 2011). Manipulation of survivin expression in mouse and rat oocytes has indicated that this IAP is necessary for correct chromosome alignment and regulation of meiotic cell cycle (Sun et al. 2009, Wang et al. 2011).

cIAP1 and -2 show similar localisation patterns to XIAP in the ovary, suggesting a possible compensatory role, which as mentioned previously may occur in certain cell types following observations in the Xiapdeficient mouse ( $\mathrm{Li}$ et al. 1998, Harlin et al. 2001, Vischioni et al. 2006). In the human ovary, XIAP's expression level is increased in granulosa cells compared with CIAP1 and -2, but levels are more similar in oocytes and OSE (Vischioni et al. 2006). In patients suffering from polycystic ovary syndrome, however, XIAP gene expression is unchanged (Das et al. 2008). 


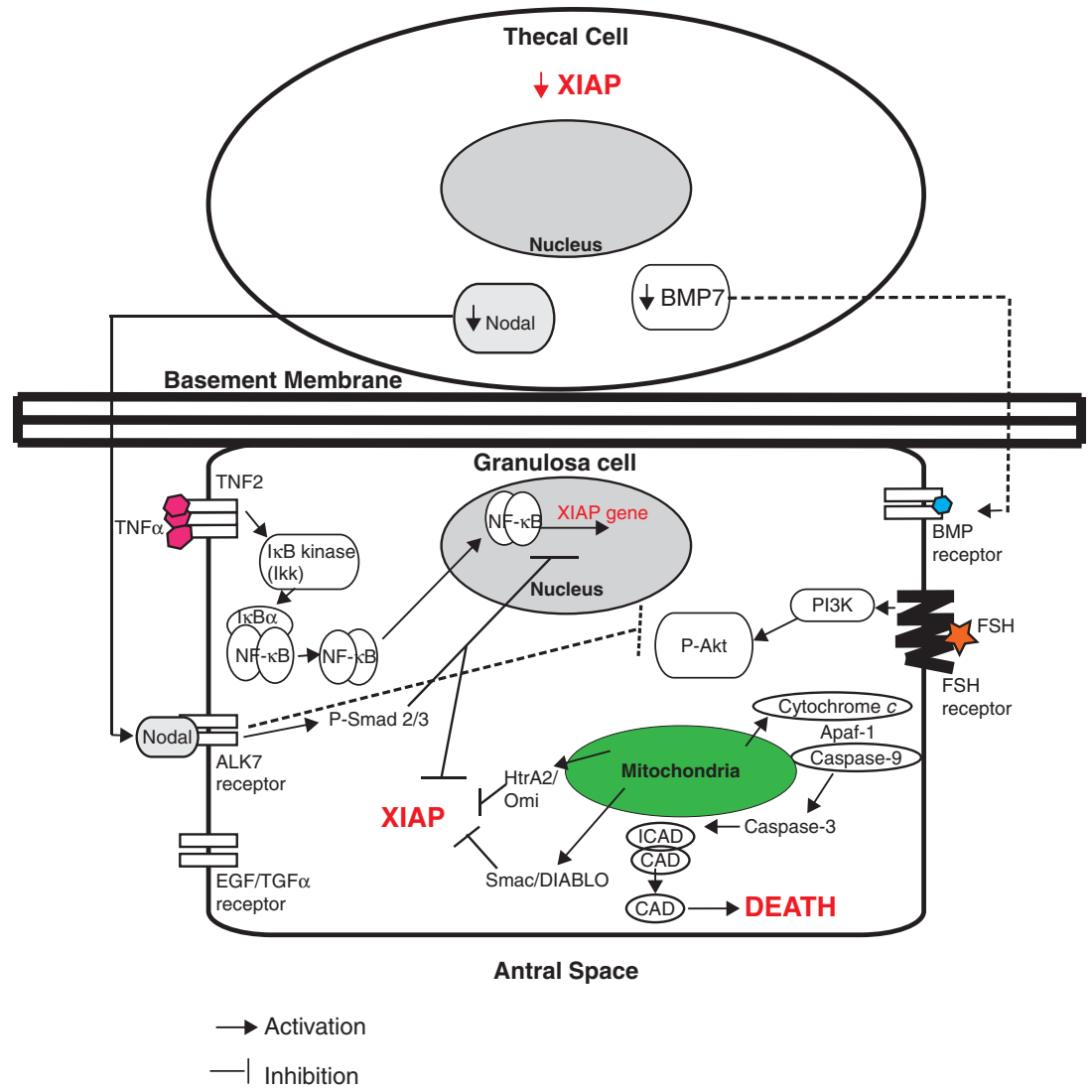

Figure 5 Proposed model of XIAP regulation in granulosa and thecal tissues from an atretic antral follicle. Dashed lines and arrows represent proposed signalling links; however, further studies are required to validate these interactions. Refer to text under 'Regulation of XIAP in the ovary' for further details and references.
In contrast, CIAP2 levels were shown to be upregulated fivefold, suggesting that functional amplification may be occurring in the ovary; however, this is in a disease state and a potential compensatory mechanism between IAPs requires further consideration in the Xiap mutant mouse model (Das et al. 2008). The ability of clAP1 and -2 to bind caspases with low affinity but not inhibit them may be the reason why ovarian research has focused on XIAP (Eckelman \& Salvesen 2006). Despite this, indirect regulation of apoptotic signalling via the TNF $\alpha$ signalling pathway has been observed in different cell types and could be a likely mechanism for apoptosis inhibition in ovarian tissue; however, further studies are required to confirm this.

\section{XIAP and the mammary gland}

Like the ovary, the mammary gland can undergo sequential rounds of development, differentiation and mass apoptosis, although in this case primarily relating to pregnancy and subsequent reversion to the nonpregnant state during weaning. XIAP expression shows developmental patterning in the mammary gland (Olayioye et al. 2005, Owens et al. 2010a). In mice, XIAP mRNA and protein levels are slightly different. The mRNA levels decrease from day 18 of pregnancy to day 8 of lactation and begin to increase again at the onset of tissue remodelling from $72 \mathrm{~h}$ of involution
(Owens et al. 2010a). XIAP protein levels, however, are unchanged at the end of pregnancy and lactation onset but decrease on day 8 of lactation until $72 \mathrm{~h}$ of involution (Owens et al. 2010a). In a study investigating the mammary gland in Xiap-deficient mice, defects in lobuloalveolar development were observed in late pregnancy, although normal development was apparent by day 7 of lactation allowing lactation to occur as normal (Olayioye et al. 2005). Consequently, XIAP may be regarded as regulating terminal differentiation of the mammary gland. Interestingly, levels of cIAP1 and -2 in the mammary gland from Xiap-deficient mice are comparable to wild type, indicating that functional compensation by other IAP family members is unlikely to occur in this tissue type (Olayioye et al. 2005). As discussed earlier, gonadotrophins stimulate XIAP expression levels to promote ovarian follicle survival; however, in the mammary gland, prolactin (PRL) is the primary hormone supporting tissue differentiation in preparation for lactation. PRL has been shown to stimulate XIAP in a number of cell types, including $\mathrm{Nb} 2$ lymphoma cells and thymocytes induced to undergo glucocorticoid-mediated apoptosis (Krishnan et al. 2001, 2003). Moreover, levels of the PRL-induced signalling molecule phospho-Stat 5 are decreased on day 16 of pregnancy in the Xiap-deficient mouse (Olayioye et al. 2005). Consequently, PRL's effect on XIAP expression during differentiation of the mammary gland 
in preparation for lactation requires further investigation. Moreover, the presence of PRL receptors on ovarian follicles suggests that PRL could also regulate XIAP in the ovary (Clarke et al. 1997, Slomczynska et al. 2001). Another study investigating anoikis, a type of cell death occurring as a result of loss of survival signals derived from the extracellular matrix (ECM), has shown XIAP to be pro-apoptotic in mammary epithelial cells (Owens et al. 2010b). This apparent challenge to the dogma regarding XIAP as an anti-apoptotic factor derives from observations that XIAP rapidly forms a molecular complex distinct from the Bax mitochondrial complex on the outer mitochondrial membrane surface following cell detachment from the ECM. XIAP together with Bax and Bak (members of the $\mathrm{Bcl} 2$ family) permeabilises the mitochondrial membrane allowing cytochrome $c$ and Smac/DIABLO to move into the cytoplasm (Owens et al. 2010b). This provides a mechanism for removal of any XIAP still residing in the cytoplasm and subsequent activation of apoptotic signalling (Owens et al. 2010b). The ability of XIAP to change between anti- and pro-apoptotic signalling may provide another component of the potential mechanism underlying the demise of the majority of ovarian follicles to atresia, which requires further investigation. This switch to apoptotic signalling could occur in response to granulosa cell detachment from underlying layers into the antral space, an early onset characteristic of follicles undergoing atresia (Fig. 6).

\section{Concluding remarks}

$\mathrm{XIAP}$ is extensively expressed in the ovary, indicating that it has a functional role in multiple cell types. In granulosa cells, there is evidence across different species for XIAP acting as a survival factor regulating follicular atresia. In contrast, its location in thecal tissue and oocytes has not been adequately explained and requires further investigation. An XIAP signalling network largely regulated by gonadotrophins has been identified and interconnects a number of different cascades emphasising the potential complexity of this system. Moreover, future studies aimed at determining how these different signalling pathways interact are necessary to broaden our understanding of how cellular XIAP levels are regulated. Furthermore, the potential presence of both IAP indirect and direct mechanisms inhibiting apoptotic signalling within the same ovarian cell types highlights redundancy
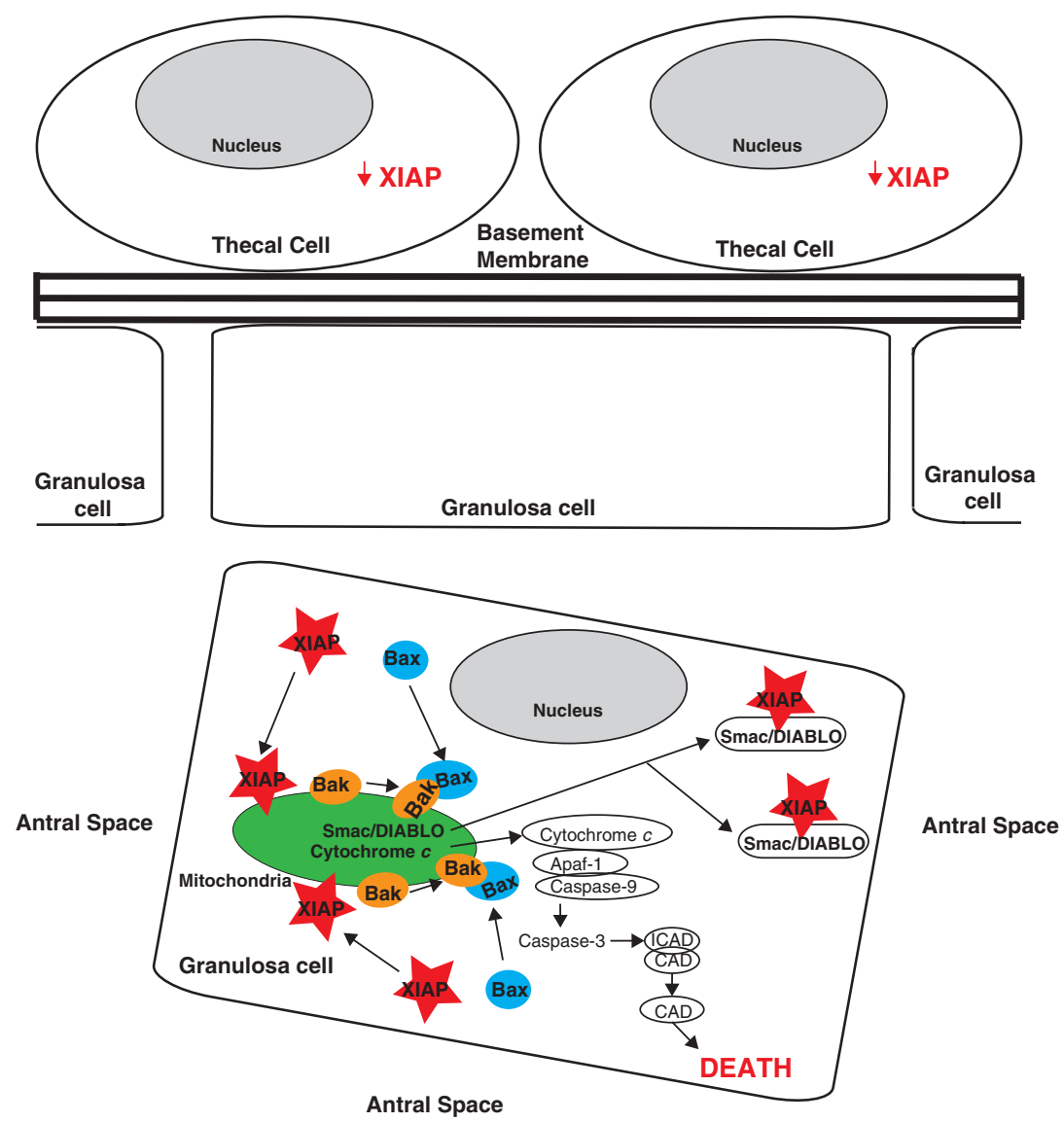

Figure 6 Hypothetical model illustrating a switch in XIAP signalling from anti-apoptotic to proapoptotic, which could potentially occur in granulosa cells following detachment from underlying cell layers or the basement membrane into the antral space. This model unlike that in Fig. 5 shows recruitment of a portion of XIAP to the mitochondrial membrane surface following cell detachment. XIAP then acts alongside Bak and Bax to induce release of cytochrome $c$ and Smac/ DIABLO. Then as in Fig. 5, Smac/DIABLO inhibits the activity of the remaining XIAP in the cytosol and cytochrome $c$ binds to Apaf- 1 leading to activation of the caspase cascade. A decrease in XIAP levels in thecal tissue like that shown in Fig. 5 is also evident. This model is based on the findings from Owens et al. $2010 \mathrm{~b}$. 
in this system. Evidence for a switch in XIAP signalling between anti- and pro-apoptotic as described in the mammary gland is intriguing, and if this also occurs in the ovary, it may indicate XIAP as pivotal in regulating not only atresia but also follicle selection and consequently follicle fate.

\section{Declaration of interest}

The authors declare that there is no conflict of interest that could be perceived as prejudicing the impartiality of the review.

\section{Funding}

The confocal microscopy work was supported by a University of Otago Postgraduate award and Department of Anatomy, University of Otago, Dunedin, New Zealand.

\section{Acknowledgements}

The authors thank Prof. Dave Grattan for providing feedback on the draft manuscript and Andrew McNaughton for technical assistance with confocal microscopy.

\section{References}

Abhari BA \& Davoodi J 2010 BIR2 domain of XIAP plays a marginal role in inhibition of executioner caspases. International Journal of Biological Macromolecules 46 337-341. (doi:10.1016/j.ijbiomac.2009.12.016)

Alnemri ES, Livingston DJ, Nicholson DW, Salvesen G, Thornberry NA, Wong WW \& Yuan J 1996 Human ICE/CED-3 protease nomenclature. Cell 87 171. (doi:10.1016/S0092-8674(00)81334-3)

Arora V, Cheung HH, Plenchette S, Micali OC, Liston P \& Korneluk RG 2007 Degradation of survivin by the X-linked inhibitor of apoptosis (XIAP)-XAF1 complex. Journal of Biological Chemistry 282 26202-26209. (doi:10.1074/jbc.M700776200)

Asselin E, Wang Y \& Tsang BK 2001 X-linked inhibitor of apoptosis protein activates the phosphatidylinositol 3-kinase/Akt pathway in rat granulosa cells during follicular development. Endocrinology 142 2451-2457. (doi:10.1210/en.142.6.2451)

Bao Q \& Shi Y 2007 Apoptosome: a platform for the activation of initiator caspases. Cell Death and Differentiation 14 56-65. (doi:10.1038/sj.cdd. 4402028)

Blankenship JW, Varfolomeev E, Goncharov T, Fedorova AV, Kirkpatrick DS, Izrael-Tomasevic A, Phu L, Arnott D, Aghajan M, Zobel K et al. 2009 Ubiquitin binding modulates IAP antagoniststimulated proteasomal degradation of c-IAP1 and c-IAP2. Biochemical Journal 417 149-160. (doi:10.1042/BJ20081885)

Chai J, Shiozaki E, Srinivasula SM, Wu Q, Dataa P, Alnemri ES \& Shi Y 2001 Structural basis of caspase-7 inhibition by XIAP. Cell 104 769-780. (doi:10.1016/S0092-8674(01)00272-0)

Cheng Y, Maeda A, Goto Y, Matsuda F, Miyano T, Inoue N, Sakamaki K \& Manabe N 2008 Changes in expression and localization of X-linked inhibitor of apoptosis protein (XIAP) in follicular granulosa cells during atresia in porcine ovaries. Journal of Reproduction and Development $\mathbf{5 4}$ 454-459. (doi:10.1262/jrd.20088)

Clarke LA, Wathes DC \& Jabbour HN 1997 Expression and localization of prolactin receptor messenger ribonucleic acid in red deer ovary during the estrous cycle and pregnancy. Biology of Reproduction 57 865-872. (doi:10.1095/biolreprod57.4.865)

Crook NE, Clem RJ \& Miller LK 1993 An apoptosis-inhibiting baculovirus gene with a zinc finger-like motif. Journal of Virology 67 2168-2174.
Dan HC, Sun M, Kaneko S, Feldman RI, Nicosia SV, Wang HG, Tsang BK \& Cheng JQ 2004 Akt phosphorylation and stabilization of X-linked inhibitor of apoptosis protein (XIAP). Journal of Biological Chemistry 279 5405-5412. (doi:10.1074/jbc.M312044200)

Das M, Djahanbakhch O, Hacihanefioglu B, Saridogan E, Ikram M, Ghali L, Raveendran M \& Storey A 2008 Granulosa cell survival and proliferation are altered in polycystic ovary syndrome. Journal of Clinical Endocrinology and Metabolism 93 881-887. (doi:10.1210/jc. 2007-1650)

Eckelman BP \& Salvesen GS 2006 The human anti-apoptotic proteins CIAP1 and CIAP2 bind but do not inhibit caspases. Journal of Biological Chemistry 281 3254-3260. (doi:10.1074/jbc.M510863200)

Fuentes-Prior P \& Salvesen GS 2004 The protein structures that shape caspase activity, specificity, activation and inhibition. Biochemical Journal 384 201-232. (doi:10.1042/BJ20041142)

Galvan V, Kurakin AV \& Bredesen DE 2004 Interaction of checkpoint kinase 1 and the X-linked inhibitor of apoptosis during mitosis. FEBS Letters $\mathbf{5 5 8}$ 57-62. (doi:10.1016/S0014-5793(03)01488-1)

Gao Z, Tian Y, Wang J, Yin Q, Wu H, Li YM \& Jiang X 2007 A dimeric Smac/DIABLO peptide directly relieves caspase- 3 inhibition by XIAP. Journal of Biological Chemistry 282 30718-30727. (doi:10.1074/jbc. M705258200)

Garrison JB, Correa RG, Gerlic M, Yip KW, Krieg A, Tamble CM, Shi R, Welsh K, Duggineni S, Huang Z et al. 2011 ARTS and Siah collaborate in a pathway for XIAP degradation. Molecular Cell 41 107-116. (doi:10. 1016/j.molcel.2010.12.002)

Gyrd-Hansen M, Darding M, Miasari M, Santoro MM, Zender L, Xue W, Tenev T, da Fonseca PCA, Zvelebil M, Bujnicki JM et al. 2008 IAPs contain an evolutionarily conserved ubiquitin-binding domain that

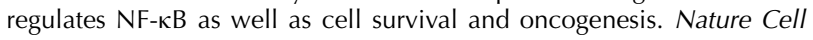
Biology 10 1309-1317. (doi:10.1038/ncb1789)

Harlin H, Reffey SB, Duckett CS, Lindsten T \& Thompson CB 2001 Characterization of XIAP-deficient mice. Molecular and Cellular Biology 21 3604-3608. (doi:10.1128/MCB.21.10.3604-3608.2001)

Hegde R, Srinivasula SM, Zhang ZJ, Wassell R, Mukattash R, Cilenti L, DuBois G, Lazebnik Y, Zervos AS, Fernandes-Alnemri T et al. 2002 Identification of Omi/HtrA2 as a mitochondrial apoptotic serine protease that disrupts inhibitor of apoptosis protein-caspase interaction. Journal of Biological Chemistry 277 432-438. (doi:10.1074/jbc.M109721200)

Hinds MG, Norton RS, Vaux DL \& Day CL 1999 Solution structure of a baculoviral inhibitor of apoptosis (IAP) repeat. Nature Structural \& Molecular Biology 6 648-651. (doi:10.1038/10701)

Holcik M, Lefebvre C, Yeh C, Chow T \& Korneluk RG 1999 A new internalribosome-entry-site motif potentiates XIAP-mediated cytoprotection. Nature Cell Biology 1 190-192. (doi:10.1038/11109)

Huang Y, Park YC, Rich RL, Segal D, Myszka DG \& Wu H 2001 Structural basis of caspase inhibition by XIAP: differential roles of the linker versus the BIR domain. Cell 104 781-790.

Johnson NC, Dan HC, Cheng JQ \& Kruk PA 2004 BRCA1 185delAG mutation inhibits Akt-dependent, IAP-mediated caspase 3 inactivation in human ovarian surface epithelial cells. Experimental Cell Research 298 9-16. (doi:10.1016/j.yexcr.2004.04.003)

Kayamori T, Kosaka N, Miyamoto A \& Shimizu T 2009 The differential pathways of bone morphogenetic protein (BMP)- 4 and -7 in the suppression of the bovine granulosa cell apoptosis. Molecular and Cellular Biochemistry 323 161-168. (doi:10.1007/s11010-008-9976-1)

Krishnan N, Buckley DJ, Zhang M, Reed JC \& Buckley AR 2001 Prolactinstimulated X-linked inhibitor of apoptosis protein expression during $\mathrm{S}$ phase cell cycle progression in rat Nb2 lymphoma cells. Endocrine $\mathbf{1 5}$ 177-186. (doi:10.1385/ENDO:15:2:177)

Krishnan N, Thellin O, Buckley DJ, Horseman ND \& Buckley AR 2003 Prolactin suppresses glucocorticoid-induced thymocyte apoptosis in vivo. Endocrinology 144 2102-2110. (doi:10.1210/en.2003-0053)

Kumar S 2007 Caspase function in programmed cell death. Cell Death and Differentiation 14 32-43. (doi:10.1038/sj.cdd.4402060)

Kumazawa Y, Kawamura K, Sato T, Sato N, Konishi Y, Shimizu Y, Fukuda J, Kodoma H \& Tanaka T 2004 HCG up-regulates survivin mRNA in human granulosa cells. Molecular Human Reproduction 11 161-166. (doi:10.1093/molehr/gah146)

Lai KW, Cheng LYL, Cheung ALM \& O WS 2003 Inhibitor of apoptosis proteins and ovarian dysfunction in galactosemic rats. Cell and Tissue Research 311 417-425. 
Lareu RR, Lacher MD, Bradley CK, Sridaran R, Friis RR \& Dharmarajan AM 2003 Regulated expression of inhibitor of apoptosis protein 3 in the rat corpus luteum. Biology of Reproduction 68 2232-2240. (doi:10.1095/ biolreprod.102.013144)

Li J, Kim JM, Liston P, Li M, Miyazaki T, Mackenzie AE, Korneluk RG \& Tsang BK 1998 Expression of inhibitor of apoptosis proteins (IAPs) in rat granulosa cells during ovarian follicular development and atresia. Endocrinology 139 1321-1328. (doi:10.1210/en.139.3.1321)

Lin SC, Huang Y, Lo YC, Lu M \& Wu H 2007 Crystal structure of the BIR1 domain of XIAP in two crystal forms. Journal of Molecular Biology 372 847-854. (doi:10.1016/j.jmb.2007.07.019)

Liston P, Fong WG, Kelly NL, Toji S, Miyazaki T, Conte D, Tamai K, Craig CG, McBurney MW \& Korneluk RG 2001 Identification of XAF1 as an antagonist of XIAP anti-caspase activity. Nature Cell Biology 3 128-133. (doi:10.1038/35055027)

Liu Z, Sun C, Olejniczak ET, Meadows RP, Betz SF, Oost T, Herrmann J, Wu JC \& Fesik SW 2000 Structural basis for binding of Smac/DIABLO to the XIAP BIR3 domain. Nature 408 1004-1008. (doi:10.1038/ 35050006)

Lu M, Lin SC, Huang Y, Kang YJ, Rich R, Lo YC, Myszka D, Han J \& Wu H 2007 XIAP induces NF- $\kappa B$ activation via the BIR1/TAB1 interaction and BIR1 dimerization. Molecular Cell 26 689-702. (doi:10.1016/j.molcel. 2007.05.006)

Mace PD, Smits C, Vaux DL, Silke J \& Day CL 2010 Asymmetric recruitment of clAPs by TRAF2. Journal of Molecular Biology 400 8-15. (doi:10. 1016/j.jmb.2010.04.055)

Martins LM, Turk BE, Cowling V, Borg A, Jarrell ET, Cantley LC \& Downward J 2003 Binding specificity and regulation of the serine protease and PDZ domains of HtrA2/Omi. Journal of Biological Chemistry 278 49417-49427. (doi:10.1074/jbc.M308659200)

Matsumoto K, Nakayama T, Sakai H, Tanemura K, Osuga H, Sato E \& Ikeda JE 1999 Neuronal apoptosis inhibitory protein (NAIP) may enhance the survival of granulosa cells thus indirectly affecting oocyte survival. Molecular Reproduction and Development 54 103-111. (doi:10.1002/(SICl)1098-2795(199910)54:2 < 103::AID-MRD 1>3.0.CO;2-V)

Mufti AR, Burstein E, Csomos RA, Graf PCF, Wilkinson JC, Dick RD, Challa M, Son JK, Bratton SB, Su GL et al. 2006 XIAP is a copper binding protein deregulated in Wilson's disease and other copper toxicosis disorders. Molecular Cell 21 775-785. (doi:10.1016/j.molcel. 2006.01.033)

Muzio M, Chinnaiyan AM, Kischkel FC, O'Rourke K, Shevchenko A, Ni J, Scaffidi C, Bretz JD, Zhang M, Gentz R et al. 1996 FLICE, a novel FADD-homologous ICE/CED-3-like protease, is recruited to the CD95 (Fas/APO-1) death-inducing signaling complex. Cell 85 817-827. (doi:10.1016/S0092-8674(00)81266-0)

Oberst A, Pop C, Tremblay AG, Blais V, Denault JB, Salvesen GS \& Green DR 2010 Inducible dimerization and inducible cleavage reveal a requirement for both processes in caspase-8 activation. Journal of Biological Chemistry 285 16632-16642. (doi:10.1074/jbc M109.095083)

Olayioye M, Kaufmann H, Pakusch M, Vaux D, Lindeman G \& Visvader J 2005 XIAP-deficiency leads to delayed lobuloalveolar development in the mammary gland. Cell Death and Differentiation 12 87-90. (doi:10.1038/sj.cdd.4401524)

Owens T, Foster FM, Tanianis-Hughes J, Cheung JY, Brackenbury L \& Streuli CH 2010a Analysis of inhibitor of apoptosis protein family expression during mammary gland development. BMC Developmental Biology 10 71. (doi:10.1186/1471-213X-10-71)

Owens TW, Foster FM, Valentijn A, Gilmore AP \& Streuli CH 2010b Role for X-linked Inhibitor of apoptosis protein upstream of mitochondrial permeabilization. Journal of Biological Chemistry 285 1081-1088. (doi:10.1074/jbc.M109.072322)

Phillipps HR, Kokay IC, Grattan DR \& Hurst PR 2011 X-linked inhibitor of apoptosis protein (XIAP) and active caspase-3 expression patterns in antral follicles in the sheep ovary. Reproduction 142 855-867. (doi:10. 1530/REP-11-0177)

Pop C, Chen YR, Smith B, Bose K, Bobay B, Tripathy A, Franzen S \& Clark AC 2001 Removal of the pro-domain does not affect the conformation of the procaspase-3 dimer. Biochemistry 40 14224-14235. (doi:10.1021/ bi011037e)
Pop C, Timmer J, Sperandio S \& Salvesen GS 2006 The apoptosome activates caspase-9 by dimerization. Molecular Cell 22 269-275. (doi:10.1016/j.molcel.2006.03.009)

Riedl SJ, Renatus M, Schwarzenbacher R, Zhou Q, Sun C, Fesik SW, Liddington RC \& Salvesen GS 2001 Structural basis for the inhibition of caspase-3 by XIAP. Cell $\mathbf{1 0 4}$ 791-800. (doi:10.1016/S00928674(01)00274-4)

Riley A, Jordan LE \& Holcik M 2010 Distinct $5^{\prime}$ UTRs regulate XIAP expression under normal growth conditions and during cellular stress. Nucleic Acids Research 38 4665-4674. (doi:10.1093/nar/gkq241)

Rotonda J, Nicholson DW, Fazil KM, Gallant M, Gareau Y, Labelle M, Peterson EP, Rasper DM, Ruel R, Vaillancourt JP et al. 1996 The threedimensional structure of apopain/CPP32, a key mediator of apoptosis. Nature Structural \& Molecular Biology 3 619-625. (doi:10.1038/ nsb0796-619)

Samuel T, Welsh K, Lober T, Togo SH, Zapata JM \& Reed JC 2006 Distinct BIR domains of CIAP1 mediate binding to and ubiquitination of tumor necrosis factor receptor-associated factor 2 and second mitochondrial activator of caspases. Journal of Biological Chemistry 281 1080-1090. (doi:10.1074/jbc.M509381200)

Schile AJ, García-Fernández M \& Steller H 2008 Regulation of apoptosis by XIAP ubiquitin-ligase activity. Genes and Development 22 2256-2266. (doi:10.1101/gad.1663108)

Scott FL, Denault JB, Riedl SJ, Shin H, Renatus M \& Salvesen GS 2005 XIAP inhibits caspase- 3 and -7 using two binding sites: evolutionarily conserved mechanism of IAPs. EMBO Journal 24 645-655. (doi:10. 1038/sj.emboj.7600544)

Scott FL, Stec B, Pop C, Dobaczewska MK, Lee JEJ, Monosov E, Robinson H, Salvesen GS, Schwarzenbacher R \& Riedl SJ 2008 The Fas-FADD death domain complex structure unravels signalling by receptor clustering. Nature 457 1019-1022. (doi:10.1038/nature07606)

Shi J, Yoshino O, Osuga Y, Nishii O, Yano T \& Taketani Y 2010 Bone morphogenetic protein 7 (BMP-7) increases the expression of folliclestimulating hormone (FSH) receptor in human granulosa cells. Fertility and Sterility 93 1273-1279. (doi:10.1016/j.fertnstert.2008.11.014)

Shiozaki EN, Chai J, Rigotti DJ, Riedl SJ, Li P, Srinivasula SM, Alnemri ES, Fairman R \& Shi Y 2003 Mechanism of XIAP-mediated inhibition of caspase-9. Molecular Cell 11 519-527. (doi:10.1016/S1097-2765(03) 00054-6)

Silke J, Kratina T, Chu D, Ekert PG, Day CL, Pakusch M, Huang DCS \& Vaux DL 2005 Determination of cell survival by RING-mediated regulation of inhibitor of apoptosis (IAP) protein abundance. PNAS 102 16182-16187. (doi:10.1073/pnas.0502828102)

Slomczynska M, Gregoraszczuk E \& Stoklosowa S 2001 Prolactin binding analysis and immunohistochemical localization of prolactin receptor in porcine ovarian cells. Endocrine Journal 48 71-80. (doi:10.1507/ endocri.48.71)

Sonenberg N \& Hinnebusch AG 2009 Regulation of translation initiation in eukaryotes: mechanisms and biological targets. Cell 136 731-745. (doi:10.1016/j.cell.2009.01.042)

Stehlik C, De Martin R, Kumabashiri I, Schmid JA, Binder BR \& Lipp J 1998 Nuclear factor (NF)-кB-regulated X-chromosome-linked iap gene expression protects endothelial cells from tumor necrosis factor $\alpha$-induced apoptosis. Journal of Experimental Medicine 188 211-216. (doi:10.1084/jem.188.1.211)

Sun C, Cai M, Gunasekera AH, Meadows RP, Wang H, Chen J, Zhang H, Wu W, Xu N, Ng SC et al. 1999 NMR structure and mutagenesis of the inhibitor-of-apoptosis protein XIAP. Nature 401 818-822. (doi:10.1038/ 44617)

Sun C, Cai M, Meadows RP, Xu N, Gunasekera AH, Herrmann J, Wu JC \& Fesik SW 2000 NMR structure and mutagenesis of the third Bir domain of the inhibitor of apoptosis protein XIAP. Journal of Biological Chemistry 275 33777-33781. (doi:10.1074/jbc.M006226200)

Sun SC, Wei L, Li M, Lin SL, Xu BZ, Liang XW, Kim NH, Schatten H, Lu SS \& Sun QY 2009 Perturbation of survivin expression affects chromosome alignment and spindle checkpoint in mouse oocyte meiotic maturation. Cell Cycle 8 3365-3372. (doi:10.4161/cc.8.20.9855)

Suzuki Y, Nakabayashi Y, Nakata K, Reed JC \& Takahashi R 2001 X-linked inhibitor of apoptosis protein (XIAP) inhibits caspase-3 and -7 in distinct modes. Journal of Biological Chemistry 276 27058-27063. (doi:10. 1074/jbc.M102415200) 
Takahashi R, Deveraux Q, Tamm I, Welsh K, Assa-Munt N, Salvesen GS \& Reed JC 1998 A single BIR domain of XIAP sufficient for inhibiting caspases. Journal of Biological Chemistry 273 7787-7790. (doi:10.1074/ jbc.273.14.7787)

Uren AG, Coulson EJ \& Vaux DL 1998 Conservation of baculovirus inhibitor of apoptosis repeat proteins (BIRPs) in viruses, nematodes, vertebrates and yeasts. Trends in Biochemical Sciences 23 159-162. (doi:10.1016/ S0968-0004(98)01198-0)

Vischioni B, van der Valk P, Span SW, Kruyt FAE, Rodriguez JA \& Giaccone G 2006 Expression and localization of inhibitor of apoptosis proteins in normal human tissues. Human Pathology 37 78-86. (doi:10. 1016/j.humpath.2005.09.022)

Wang Y, Asselin E \& Tsang BK 2002a Involvement of transforming growth factor $\alpha$ in the regulation of rat ovarian $X$-linked inhibitor of apoptosis protein expression and follicular growth by follicle-stimulating hormone. Biology of Reproduction 66 1672-1680. (doi:10.1095/bio Ireprod66.6.1672)

Wang Y, Chan S \& Tsang BK 2002 Involvement of inhibitory nuclear factor$\kappa \mathrm{B}(\mathrm{NF} \kappa \mathrm{B})$-independent $\mathrm{NF} \kappa \mathrm{B}$ activation in the gonadotropic regulation of X-linked inhibitor of apoptosis expression during ovarian follicular development in vitro. Endocrinology 143 2732-2740. (doi:10.1210/en. 143.7.2732)

Wang Y, Rippstein PU \& Tsang BK 2003 Role and gonadotrophic regulation of X-linked inhibitor of apoptosis protein expression during rat ovarian follicular development in vitro. Biology of Reproduction 68 610-619. (doi:10.1095/biolreprod.102.007807)

Wang H, Jiang JY, Zhu C, Peng C \& Tsang BK 2006 Role and regulation of nodal/activin receptor-like kinase 7 signaling pathway in the control of ovarian follicular atresia. Molecular Endocrinology 20 2469-2482. (doi:10.1210/me.2005-0446)
Wang K, Jiang GJ, Wei L, Liang XW, Miao DQ, Sun SC, Guo L, Wang ZB \& Lu SS 2011 Survivin is a critical regulator of spindle organization and chromosome segregation during rat oocyte meiotic maturation. Zygote 19 307-313. (doi:10.1017/S0967199409990359)

Wu G, Chai J, Suber TL, Wu JW, Du C, Wang X \& Shi Y 2000 Structural basis of IAP recognition by Smac/DIABLO. Nature 408 1008-1012. (doi:10. 1038/35050012)

Xiao CW, Ash K \& Tsang BK 2001 Nuclear factor-кB-mediated X-linked inhibitor of apoptosis protein expression prevents rat granulosa cells from tumor necrosis factor $\alpha$-induced apoptosis. Endocrinology 142 557-563. (doi:10.1210/en.142.2.557)

Yang Y, Fang S, Jensen JP, Weissman AM \& Ashwell JD 2000 Ubiquitin protein ligase activity of IAPs and their degradation in proteasomes in response to apoptotic stimuli. Science 288 874-877. (doi:10.1126/ science.288.5467.874)

Zou H, Henzel WJ, Liu X, Lutschg A \& Wang X 1997 Apaf-1, a human protein homologous to $C$. elegans CED-4, participates in cytochrome $C$ dependent activation of caspase-3. Cell 90 405-413. (doi:10.1016/ S0092-8674(00)80501-2)

Zou H, Li Y, Liu X \& Wang X 1999 An APAF-1 cytochrome $c$ multimeric complex is a functional apoptosome that activates procaspase-9. Journal of Biological Chemistry 274 11549-11556. (doi:10.1074/jbc. 274.17.11549)

Received 17 April 2012

First decision 10 May 2012

Accepted 30 May 2012 